\title{
Desenvolvimento do judô paralímpico na extensão universitária: um estudo de caso
}

\author{
Development of paralympic judô in university extension: a case study \\ DOI: http://dx.doi.org/10.36453/2318-5104.2018.v16.n1.p117
}

\author{
Gustavo Bordin Schumacher, Felippe Marchetti, Janice Zarpellon Mazo
}

Universidade Federal do Rio Grande do Sul (UFRGS)

\section{RESUMO}

Este estudo tem como objetivo investigar o caso do desenvolvimento do judô paralímpico no estado do Rio Grande do Sul, enfocando o projeto de extensão universitária Bugre Lucena (PBL) da Escola de Educação Física, Fisioterapia e Dança (ESEFID), da Universidade Federal do Rio Grande do Sul (UFRGS) A pesquisa se caracteriza como descritiva do tipo estudo de caso, realizada através de análise documental dos relatórios do PBL e projetos correlatos, além dos boletins oficiais da Confederação Brasileira de Desportos de Deficientes Visuais (CBDV) e do Comitê Paralímpico Brasileiro (CPB). Os dados coletados referentes aos anos de 2005 a 2017 foram categorizados utilizando como ferramenta de análise os nove pilares do modelo Sport Policy Factors Leading to International Sporting Success (SPLISS). A prática sistematizada do judô paralímpico no Rio Grande do Sul (RS) iniciou no PBL e se desenvolveu em parceira com a Associação de Cegos do Rio Grande do Sul (ACERGS). A Equipe ACERGS/UFRGS, foi constituída e permaneceu como única filiada do RS na CBDV até o ano de 2017. Este estudo demonstra que a vinculação do judô paralímpico com projetos de extensão universitária pode ser um meio de viabilizar a prática esportiva de forma estruturada (da iniciação esportiva ao alto rendimento), com a utilização das instalações esportivas e dos recursos humanos (suporte técnico) oriundos da universidade. Além dos estudantes adquirirem tal experiência na sua formação acadêmica, as entidades com poucos recursos financeiros podem oferecer a modalidade aos seus associados.

PALAVRAS-CHAVE: Judô Paralímpico; Extensão Universitária; Gestão Esportiva.

\section{ABSTRACT}

This study aims to investigate the development of paralympic judo in the State of Rio Grande do Sul, focusing on the University Extension Project Bugre Lucena (PBL) of the School of Physical Education, Physiotherapy and Dance (ESEFID), Federal University of Rio Grande do Sul (UFRGS) The research is characterized as descriptive of the case study type, performed through documentary analysis of the PBL reports and related projects, in addition to the official bulletins of the Brazilian Visually Impaired Sports Confederation and the Brazilian Paralympics Committee. The data collected for the years 2005 to 2017 were categorized using the analysis of the nine pillars of the Sport Policy Factors Leading to International Sporting Success (SPLISS) model. The systematized practice of Paralympic Judo in Rio Grande do Sul (RS) began in the PBL and developed in partnership with the Rio Grande do Sul Blind Association (ACERGS). The ACERGS/UFRGS Team was constituted and remained the only member of the RS in the CBDV until 2017. This study demonstrates that the linkage of Paralympic judo with university extension projects can be a means of making sport practiced in a structured way (from sports initiation to high performance), through the use of sports facilities and human resources from the university. In addition to students acquiring such experience in their academic training, entities with few financial resources can offer the modality to their associates.

KEYWORDS: Paralympic Judo; University Extension; Sports Management. 


\section{INTRODUÇÃO}

O judô paralímpico foi o primeiro esporte de combate a fazer parte do programa dos Jogos Paralímpicos (JP) de verão (CBDV, 2017). Praticado exclusivamente por atletas deficientes visuais, foi inserido em 1988, nos JP de Seul, contando apenas com a participação de atletas homens. As disputas no judô paralímpico feminino ocorreram pela primeira vez nos JP de verão de Atenas, em 2004. No cenário internacional, os primeiros relatos da modalidade datam da década de 1970 (BRASIL, 2017), começando a ser praticado de forma efetiva e sistematizada no Brasil em 1982, no Instituto Benjamin Constant (IBC) no Rio de Janeiro (VIEIRA; SOUZA JR., 2006).

Tendo em vista que o judô paralímpico é uma modalidade praticada por atletas deficientes visuais, faz-se necessário uma classificação oftalmológica, considerada como critério de elegibilidade do atleta em qualquer competição. Para tanto, utiliza-se a letra B de "blind" (cego, em inglês), seguido dos números 1, 2 e 3, de tal modo: o atleta B1 é cego, o B2 possui percepção de vultos e o B3 definição de imagem. A despeito disso, os atletas das três classes referidas acima disputam entre si, diferenciados unicamente em categorias de peso (IBSA, 2018). O principal aspecto que distingue o judô paralímpico do judô olímpico é que no primeiro, devido a deficiência visual, o combate é iniciado com os atletas fazendo a pegada no quimono do seu oponente e este contato deve ser permanente. $E$, sempre que houver perda de contato a luta é paralisada e os atletas são recolocados na posição inicial do combate.

Em uma posição de destaque na modalidade de judô paralímpico, o Brasil ocupa a quinta posição no quadro geral de medalhas em Jogos Paralímpicos, com o total de 22 medalhas, sendo quatro de ouro, nove de prata e nove de bronze (IPC, 2017). Diante destes expressivos resultados é relevante compreender como ocorreu o desenvolvimento da modalidade paralímpica nos estados e cidades brasileiras. No caso do Rio Grande do Sul encontraram-se indícios que sugerem o pioneirismo do PBL na introdução de tal modalidade paralímpica no estado.

Diante disso, o presente estudo tem como objetivo investigar o caso do desenvolvimento do judô paralímpico no estado do Rio Grande do Sul, enfocando o projeto de extensão universitária Bugre Lucena (PBL) da Escola de Educação Física, Fisioterapia e Dança (ESEFID), da Universidade Federal do Rio Grande do Sul (UFRGS).

\section{MÉTODOS}

A pesquisa se caracteriza como descritiva do tipo estudo de caso (YIN, 2001; GONSALVES, 2007), realizada através de análise documental dos relatórios do PBL, de projetos vinculados da ESEFID/UFRGS e dos boletins oficiais da Confederação Brasileira de Desportes de Deficientes Visuais (CBDV) e do Comitê Paralímpico Brasileiro (CPB). Além disso, foi realizada uma revisão bibliográfica sobre o assunto. A coleta de dados foi demarcada no período de 2005, quando houve a organização da primeira turma de atletas deficientes visuais do Rio Grande do Sul, até 2017, ano que marca a participação da equipe de judô do PBL no Grand Prix INFRAERO de Judô para Cegos, realizado em Porto Alegre (RS).

Os dados coletados no referido período (2005-2017) foram categorizados em nove grupos, de acordo com o modelo de De Bosscher et al. (2006), o qual é denominado Sports Policiy Factors Leading to Internacional Sporting Success (SPLISS). O Consórcio SPLISS é um dos principais responsáveis pelas pesquisas científicas que comparam as políticas para o esporte de alto rendimento e analisa fatores de sucesso internacional. Desde 2002, o Consórcio SPLISS foca suas pesquisas nos esportes olímpicos e, atualmente, conta com a colaboração de 15 países, dentre eles o Brasil (SPLISS, 2017). No âmbito olímpico, sua aplicação vem sendo adaptada para modalidades específicas, como canoagem (SOTIRIADOU et al., 2013), atletismo (TRUYENS et al., 2014), tênis (BROUWERS et al., 2015) e judô (MAZZEI, 2015).

A escolha pelo SPLISS deve-se ao seu direcionamento para o esporte de alto rendimento, perspectiva atingida pela equipe de judô paralímpico do PBL nos últimos anos. Vale mencionar que está em andamento a adaptação do SPLISS para os esportes paralímpicos, o Para-Sport Policy Factors Leading to International Sporting Sucess (PARA-SPLISS), com previsão de conclusão para o ano de 2018 (PARASPLISS, 2018). O SPLISS 
indica os principais fatores que levam ao sucesso esportivo internacional por meio de nove pilares, a saber: pilar um - suporte financeiro; pilar dois - organização e estrutura das políticas esportivas; pilar três - participação e esporte de base; pilar quatro - identificação e sistemas de desenvolvimento de talentos esportivos; pilar cinco - suporte para atletas e pós carreira; pilar seis - instalações esportivas; pilar sete - desenvolvimento e suporte para técnicos; pilar oito - competições nacionais e internacionais e pilar nove - pesquisas científicas. Antes de apresentar os resultados da análise dos dados através dos pilares do modelo SPLISS, delineamos um panorama do PBL e o desenvolvimento do Judô Paralímpico no Rio Grande do Sul (RS).

\section{Projeto de extensão universitária Bugre Lucena e o Judô Paralímpico}

Os primeiros indícios da prática de judô por atletas deficientes visuais no RS, correspondem à chegada da modalidade ao Brasil e referem-se a atletas que começaram a sua prática em clubes ou academias tradicionais, treinando junto a atletas sem deficiência. Esse foi o caso da atleta Giovana Pilla, que começou a praticar o judô em 1979, na cidade de Canoas/RS, nas instalações da Petrobras. A partir de então, a atleta vinculou-se à Federação Gaúcha de Judô (FGJ) e passou a participar de competições de judô contra oponentes sem a deficiência.

Situações semelhantes ocorreram até a primeira ação de promoção da prática do judô paralímpico no Rio Grande do Sul em 2005. Tal ação ocorreu pela iniciativa do aluno de graduação da Escola de Educação Física da UFRGS e faixa preta de judô, Darci Barnech Campani, responsável pela criação de uma turma de judô específica para alunos deficientes visuais dentro do PBL, contando com a parceria do Centro Louis Braille. A turma do PBL de judô para deficientes visuais iniciou suas atividades no dia quatro de junho de 2005 (BUGRE LUCENA, 2005), com a participação de quatro atletas, sendo três cegos e um com baixa visão. As aulas eram ministradas aos sábados pela manhã, com duas horas de duração, no ginásio de lutas da ESEFID (CAMPANI; KRUMEL; SCHNEIDER, 2010).

O PBL, da ESEFID/UFRGS, foi criado em 1991 pelo Professor Dr. Alexandre Velly Nunes e recebeu este nome em homenagem ao professor Bugre Ubirajara Marimon de Lucena, responsável pela introdução da disciplina de judô no currículo da ESEFID/UFRGS no ano de 1962 (TRUSZ; NUNES, 2007). Nos anos iniciais, o PBL oferecia a prática de judô para crianças e adolescentes oriundos de diversas regiões de Porto Alegre e para acadêmicos da UFRGS, visando à inclusão social de crianças e adolescentes em situação de risco através do ensino e prática de atividades de combate (TRUSZ; NUNES, 2007). Com o passar dos anos, o PBL cresceu tanto em número de participantes quanto em relação à oferta de modalidades de combate e, além disso, passou a atender deficientes visuais e auditivos.

Com o objetivo de desenvolver uma metodologia de ensino do judô apropriada para as pessoas com deficiência no dia 11 de maio de 2006, foi criado o projeto de extensão universitária, vinculado ao PBL, intitulado, "Judô para portadores de necessidades especiais". Além de oportunizar o desenvolvimento das capacidades motoras através da prática do judô, outro objetivo deste projeto era promover uma "articulação com as instituições e entidades representativas do setor social" (JUDÔ PARA PORTADORES DE NECESSIDADES ESPECIAIS, 2006). Em razão disso, a carga horária das aulas foi ampliada para quatro, mas as atividades prosseguiram sendo oferecidas apenas aos sábados. Tal projeto perdurou por quatro anos, sendo coordenado no primeiro ano pelo professor Dr. Alexandre Velly Nunes e, posteriormente, nos três anos seguintes pelo professor Darci Barnech Campani. Durante os primeiros cinco anos das atividades do judô paralímpico no $\mathrm{PBL}$, houve um desenvolvimento tão significativo dos atletas deficientes visuais bem como dos professores, que se tornou viável a prática conjunta de judô por atletas videntes e deficientes visuais, sem riscos ou ônus para ambos. De tal modo, foi desencadeado um processo de adaptação do grupo a está nova metodologia de trabalho coletivo.

Outra mudança ocorreu no final do ano de 2009, quando a PBL se vinculou a Associação de Cegos do Rio Grande do Sul (ACERGS), que retomou as atividades na área esportiva depois da mudança de diretoria. A ACERGS é uma entidade de representação para cegos e pessoas com baixa visão no Rio Grande do Sul (ACERGS, 2018) e tem como atividade principal a prestação de serviços de assistência social para tal público. Com a nova diretoria, a ACERGS passou a oferecer aos seus associados às modalidades de futebol de cinco, futebol B2/ B3, goalball, judô paralímpico, atletismo e xadrez (ACERGS, 2018). A parceria resultou na formação da equipe 
ACERGS/UFRGS de judô paralímpico, a qual é mantida e gerenciada pelo PBL.

A Equipe ACERGS/UFRGS, conforme registros oficiais, participou da primeira etapa do Grand Prix INFRAERO de Judô para Cegos, realizada em Goiânia/GO, em 2010. Já nesta primeira participação foi representada por quatro atletas e conquistou cinco medalhas. Na segunda etapa do Grand Prix, realizado em São Paulo/SP, com uma delegação de seis atletas, conquistou seis medalhas, sendo três de ouro, garantindo a primeira colocação da equipe, na categoria iniciante. Vale a ressalva, que o evento foi promovido pela CBDV, entidade regulamentadora do judô paralímpico brasileiro, fundada em 2008. No ano seguinte, em 2009, a CBDV obteve o patrocínio da Empresa Brasileira de Infraestrutura Aeroportuária (INFRAERO) à modalidade.

Com a participação dos atletas da Equipe ACERGS/UFRGS em competições nacionais e internacionais organizadas pela CBDV, tornou-se imperativo a qualificação e readequação do PBL a este novo contexto. Nessa direção, no ano de 2013, foi criado pelo professor Dr. Alexandre Velly Nunes um projeto de extensão universitária, vinculado ao PBL, intitulado "Preparação Física para Deficientes Visuais (PFDV)". Esclarecemos que os projetos de extensão universitária são reeditados anualmente e, por isso, o PFDV está na sexta edição, enquanto o PBL encontra-se na sua 28 a edição se caracterizando como um dos mais longevos projetos de extensão universitária da UFRGS. Devido a esta longa trajetória, entendeu-se a necessidade de fazer um estudo mais detalhado do PBL e, para tanto, se optou em utilizar como parâmetro o modelo SPLISS.

\section{RESULTADOS}

Uma análise do judô paralímpico do projeto Bugre Lucena

Neste tópico, apresentamos as informações obtidas por meio da utilização dos nove pilares do modelo SPLISS, como categorias de análise do desenvolvimento esportivo do judô paralímpico do PBL.

\section{Suporte financeiro}

Esse pilar trata da entrada de recursos públicos no sistema esportivo, o que possibilita a implementação dos processos referentes aos demais pilares. Segundo De Bosscher et al. (2015) existe uma forte relação entre os recursos financeiros disponíveis e o sucesso esportivo internacional, sendo o financiamento esportivo para o esporte de alto rendimento um importante preditor de resultados. No caso, do PBL, ao longo dos anos foi contemplado por recursos financeiros oriundos de editais, como o PROEX/MEC do Ministério do Esporte, enquanto projeto para o período de execução do ano de 2013, e novamente em 2014, como programa para o período de execução de dois anos (biênio 2015/2016). Tal edital proporcionou o financiamento de projetos de extensão universitária, valorizando as iniciativas nas universidades públicas brasileiras; todavia, não foi reeditado no período de 2017/2018.

Atualmente, a bolsa de extensão universitária oferecida exclusivamente a alunos da graduação da UFRGS (PROREXT, 2018) é a única fonte de recursos financeiros aplicados na modalidade de judô paralímpico do PBL. Para ser contemplado, as cotas de bolsas de extensão universitárias devem ser solicitadas anualmente pelo coordenador das atividades, passando pelos processos de inscrição e seleção da Comissão de Avaliação. 0 número de bolsas de extensão não é suficiente para atender todas as demandas e, além disso, precisam ser renovadas anualmente.

No ano de 2017, o PBL foi contemplado com duas bolsas de extensão universitária e uma bolsa PRAE (Pró-Reitoria de Assuntos Estudantis) (BUGRE LUCENA, 2017). Já o Projeto de Preparação Física para Atletas Deficientes Visuais, recebeu uma bolsa de extensão universitária e contou com a participação voluntária de um professor como coordenador e ministrante. Como o PBL funciona ininterruptamente durante todo o ano, no período dos trâmites burocráticos do processo de solicitação de bolsas de extensão, os bolsistas remunerados continuam atuando na condição de bolsistas voluntários, mesmo sem saber se serão ou não contemplados com bolsas. Além disso, eles não recebem retroativamente pela prestação de serviço executado no período. A atuação dos bolsistas nas referidas condições representa uma contribuição fundamental, tendo em vista a preparação da Equipe ACERGS/UFRGS para o Grand Prix Internacional INFRAERO de Judô para Cegos que 
ocorre sempre no começo do ano em São Paulo.

\section{Organização e estrutura das políticas esportivas}

É um pilar que trata da estrutura organizacional das instituições esportivas. Segundo De Bosscher et al. (2015) esse é o item de maior complexidade na avaliação dos sistemas de desenvolvimento do esporte, graças a grande diversidade de sistemas e estruturas existentes em diferentes localidades. Os elementos a serem analisados aqui são planejamento de longo prazo e o envolvimento e participação de todas organizações envolvidas e suas diligências.

A ACERGS possui vínculo com a CBDV nas modalidades de goalball, futebol de cinco e judô. Na modalidade de judô, ficou acordado que a equipe leva o nome de ACERGS/UFRGS, devido a centralização da coordenação da modalidade pelo PBL da ESEFID/UFRGS. Além da filiação na modalidade de judô paralímpico através da ACERGS, os atletas deficientes visuais do PBL, são também filiados à Federação Gaúcha de Judô (FGJ) e a Confederação Brasileira de Judô (CBJ) e participam, ativamente, das competições de judô olímpico pela Equipe Bugre Lucena da ESEFID/UFRGS.

O Planejamento do PBL é anual para todas as suas modalidades, inclusive o judô paralímpico, visto que a cada ano o projeto precisa ser reeditado, dificultando o planejamento de longo prazo. De certo modo, pode-se dizer que o projeto é mantido em partes, devido ao trabalho voluntário de alguns professores. O PBL não conta com nenhum tipo de patrocínio externo e os processos decisórios são feitos pela Comissão Coordenadora, composta por quatro professores faixas preta.

\section{Participação esportiva}

O pilar três versa sobre a participação esportiva no sentido de oportunizar de experiências relacionadas às modalidades, desde o âmbito escolar até a idade adulta. No caso específico do judô paralímpico, tais informações podem ser auferidas através da checagem do número de participantes em relação ao universo de deficientes existentes na localidade. Isto é verificar se há elevado número de locais que oferecem a prática esportiva adaptada e se há uma política, que inclua aporte financeiro, para o desenvolvimento da qualidade da modalidade nos locais de prática.

Segundo o IBGE (2010) o número de pessoas deficientes visuais em Porto Alegre é de 249.804 pessoas. Em 2017, a Equipe ACERGS/UFRGS contou com a participação de 16 atletas, 10 são atletas do PBL e os outros seis, são atletas de outros clubes do RS que não possuem filiação com a CBDV. Quando comparados, os números de deficientes visuais em relação com o número de atletas de judô paralímpico do PBL é muito baixo. Entretanto, ao analisar-se o número de atletas inscritos nos eventos de judô paralímpico da CBDV, constata-se que a Equipe ACERGS/UFRGS é recorrentemente uma das maiores delegações. Podemos afirmar que a baixa participação esportiva de pessoas com deficiência visual no judô paralímpico é um fenômeno nacional.

O PBL atende a crianças e adolescentes das redes pública e privada de ensino de Porto Alegre, deficientes visuais e auditivos, acadêmicos da UFRGS e comunidade em geral. Os inscritos são alocados de acordo com a faixa etária, nível de desenvolvimento na modalidade e interesse competitivo. Os treinos de judô da Equipe ACERGS/UFRGS ocorrem de segunda a sextas das $19 \mathrm{~h} 30 \mathrm{~min}$ às $21 \mathrm{~h}$. Já a preparação física ocorre de dois a cinco dias por semana, de acordo com o nível e objetivo do atleta. A Equipe ACERGS/UFRGS é bastante heterogênea em idade com atletas entre 18 e 51 anos, também em interesse, pois há casos de reabilitação, lazer, convívio social e alto rendimento. A despeito disso, todos participam das competições da CBDV, se ausentando apenas por falta de recursos financeiros para pagar as despesas da viagem.

\section{Identificação e sistemas de desenvolvimento de talentos esportivos}

O pilar quatro, diz respeito a identificação e desenvolvimento de talentos esportivos, sendo voltado ao processo de detecção, seleção e promoção dos mesmos. Alguns fatores importantes são: existência de um processo sistemático para identificação de potenciais atletas; a padronização das análises para os treinadores; 
existência de um sistema de testagem e monitoramento da evolução dos atletas; e o auxílio por pesquisas científicas.

Apesar do alto rendimento não ser o objetivo principal do PBL, a identificação do talento esportivo ocorre, porém sem um processo sistematizado. $O$ atleta é monitorado nos treinos e em competições, tendo seus combates gravados em vídeos, os quais após análise são utilizados pelo técnico para em conjunto com o atleta, elaborar correções técnicas e táticas, dentro de uma periodização de treinamentos específicos de judô.

Como resultados deste modelo, podemos citar o atleta do PBL, Anderson Wassian da Silva, convocado para todas as fases de treinamento da seleção brasileira de judô paralímpico em 2017. Além dele, a atleta Thais Gonçalves que encerrou o ano de 2017, como a segunda colocada da sua categoria no ranking nacional da CBDV. Esses foram atletas evidenciados nos últimos anos.

\section{Suporte para atletas e pós-carreira}

O pilar cinco trata do suporte de serviços que os atletas recebem do início de sua carreira até o direcionamento quando a encerram, visto que a dedicação exclusiva durante anos a uma modalidade é um fator complicador para o desenvolvimento de uma formação profissional complementar. Aqui é preciso analisar se os atletas possuem algum tipo de aconselhamento psicológico, legal, de transição entre a base e o profissional e de incentivo a qualificação profissional em outras áreas, caso o esporte não seja a principal fonte de renda do sujeito.

O principal suporte na carreira e no pós-carreira dos atletas de judô paralímpicos do PBL é no direcionamento, enfatizando a importância dos estudos, como a conclusão do ensino médio e ingresso na universidade. Além disso, o incentivo e apoio para sua qualificação profissional. Para tanto, ocorre a criação de novas turmas e alterações de horários dos treinos a fim de minimizar possíveis conflitos de horário entre estudo/trabalho e os treinos.

\section{Instalações esportivas}

O pilar seis refere-se à qualidade das instalações esportivas destinadas ao treinamento de atletas e o acesso aos espaços. Esse pilar também abrange a disponibilidade de serviços complementares na instalação, como a atuação de médicos, fisioterapeutas, nutricionistas e preparadores físicos.

O PBL funciona desde de 1999 no Ginásio Bugre Lucena da ESEFID/UFRGS, um espaço voltado para a prática das ginásticas e lutas (LUME, 2018). A instalação conta com 165 tatames de $2 \mathrm{~m} \times 1 \mathrm{~m}$ (mesmo material utilizado nos Jogos Olímpicos de Sydney em 2000), posicionados sobre um sistema único no Brasil de plataforma de amortecimento, especialmente desenvolvida para o PBL, com o auxílio do Aurélio Miguel, primeiro campeão olímpico brasileiro de judô. Além disso, possui equipamentos de musculação, utilizados na preparação física dos atletas, e assim como o acesso dos atletas e acesso a Clínica de Fisioterapia da ESEFID/UFRGS. Os atletas possuem acompanhamento dos técnicos de judô, preparadores físicos e fisioterapeutas.

\section{Desenvolvimento e suporte para técnicos}

O pilar sete, alude o número de treinadores com boa formação e experiência, a oportunidade de aperfeiçoamento educacional e a possibilidade de profissionalização. Também, faz referência a se manterem financeiramente com tal prática e o nível de reconhecimento profissional no desenvolvimento de suas funções.

Além de oferecer a prática do judô a comunidade, o PBL tem como objetivo a formação de profissionais, o desenvolvimento acadêmico e o treinamento especializado do judô, com uma proposta inovadora na metodologia do ensino da modalidade, como a integração do tradicional método japonês, com o método alemão e cubano (BUGRE LUCENA, 2017). São exemplos da formação de técnicos do PBL, o atual técnico e auxiliar técnico da Equipe ACERGS/UFRGS. A qualidade dos técnicos é um dos principais fatores do sucesso esportivo do judô uma vez que qualificados e motivados os técnicos podem ter um efeito multiplicativo no desenvolvimento do judô em um país (MAZZEI, 2015). 
A CBDV tem procurado investir no desenvolvimento e suporte aos técnicos e gestores das suas entidades afiliadas. O técnico da Equipe ACERGS/UFRGS de judô paralímpico, Gustavo Bordin Schumacher, esteve presente como convidado da CBDV nos Jogos Paralímpicos do Rio de Janeiro, em 2016, com o objetivo de analisar, discutir e ampliar os conhecimentos sobre a modalidade (UFRGS, 2018). Além de participar do II Seminário de Capacitação Paradesportiva de Cegos, organizado pelo CPB e CBDV, no Centro de Treinamento Paralímpico, em São Paulo (CBDV, 2018). A profissionalização e valorização dos técnicos de judô paralímpico no Brasil e sua consequente manutenção financeira ainda é uma realidade muito distante. A maioria dos técnicos atuam de forma voluntária nas entidades, como no caso do técnico da Equipe ACERGS/UFRGS.

\section{Competições nacionais e internacionais}

O pilar oito relaciona-se com o número de eventos nacionais e internacionais que contaram com a participação do PBL, oportunizando experiência competitiva para os atletas. Segundo Brouwers (2014), no tênis, os pilares de competições nacionais e internacionais e o de suporte para técnicos, parecem ser os mais importantes para o sucesso da modalidade no alto rendimento.

O calendário competitivo do judô paralímpico brasileiro é restrito a três competições anuais: duas etapas do Grand Prix INFRAERO de Judô para Cegos (internacional e nacional) organizadas pela CBDV, Paralimpíadas Escolares, evento escolar nacional gerido pelo CPB. O PBL esteve presente em todas as competições organizadas pela CBDV no período de 2011 até 2017, participando nas categorias, iniciantes, escolares e adultos. Ao longo deste período, 81 entidades participaram destes eventos; entretanto, somente a Equipe ACERGS/UFRGS e o Caixa Escolar do Instituto Benjamim Constant (CEIBC) do Rio de Janeiro estiveram presentes em todas as etapas. Durante o período de 2011 a 2017, o judô paralímpico gaúcho foi representado por 25 atletas, sendo 21 deles oriundos do PBL (Tabela 1).

Tabela 1. Eventos e participantes da Equipe ACERGS/UFRGS em cada categoria em competições organizadas pela CBDV de 2011 a 2017.

\begin{tabular}{clccc}
\multirow{2}{*}{ Evento } & \multicolumn{1}{c}{ Local } & $\begin{array}{c}\text { Atletas } \\
\text { participantes }\end{array}$ & \multicolumn{2}{c}{ Categorias } \\
& Iniciantes & Adultos \\
\hline GP 2011/1 & Goiânia/GO & 4 & 2 & 2 \\
GP 2011/2 & São Paulo/SP & 6 & 4 & 2 \\
GP 2012/1 & São Paulo/SP & 10 & 8 & 2 \\
GP 2012/2 & Belo Horizonte/BH & 8 & 6 & 2 \\
GP 2013/1 & São Paulo/SP & 9 & 5 & 4 \\
GP 2013/2 & Natal/RN & 11 & 7 & 4 \\
GP 2014/1 & São Paulo/SP & 5 & 3 & 2 \\
GP 2014/2 & Campo Grande/MS & 8 & 3 & 5 \\
GP 2015/1 & São Paulo/SP & 13 & 8 & 5 \\
GP 2015/2 & Porto Alegre/RS & 16 & 9 & 7 \\
GP 2016/1 & Rio de Janeiro/RJ & 14 & 7 & 7 \\
GP 2016/2 & Belém/PA & 10 & 2 & 8 \\
GP 2017/1 & São Paulo/SP & 12 & 2 & 10 \\
GP 2017/2 & Porto Alegre/RS & 16 & 4 & 12 \\
\hline
\end{tabular}

Fonte: adaptado de CBDV (2018).

Ao observar a Tabela 2, percebe-se bons resultados da Equipe ACERGS/UFRGS, que juntamente com o CEIBC, são as maiores vencedoras na categoria iniciantes, com cinco títulos cada. Na categoria adulto, o 
CEIBC e o Centro de Emancipação Social e Desportiva de Cegos (CESEC) ganharam cinco títulos cada. A melhor colocação da Equipe ACERGS/UFRGS na categoria adulto, foi a quarta colocação em 2016 e 2017, ambas na etapa nacional do Grand Prix INFRAERO de Judô para Cegos.

Tabela 2. Resultados individuais ${ }^{1}$ e classificações da Equipe ACERGS/ UFRGS em competições organizadas pela CBDV de 2011 a 2017.

\begin{tabular}{|c|c|c|c|c|c|c|c|c|}
\hline \multirow{2}{*}{ Evento/Etapa } & \multicolumn{3}{|c|}{ Iniciantes } & \multicolumn{3}{|c|}{ Adultos } & \multicolumn{2}{|c|}{ Classificação Geral } \\
\hline & $\mathrm{Ou}$ & $\operatorname{Pr}$ & $\mathrm{Br}$ & $\mathrm{Ou}$ & $\operatorname{Pr}$ & $\mathrm{Br}$ & Iniciante & Adulto \\
\hline GP 2011/1 & 0 & 1 & 1 & 0 & 1 & 2 & ---- & 13ㅇ lugar \\
\hline GP 2011/2 & 2 & 1 & 1 & 1 & 1 & 0 & 10 lugar & 7ㅇ lugar \\
\hline GP 2012/1 & 2 & 2 & 4 & 1 & 0 & 1 & 20 lugar & 70 lugar \\
\hline GP 2012/2 & 3 & 0 & 1 & 1 & 0 & 0 & 10 lugar & 70 lugar \\
\hline GP 2013/1 & 4 & 1 & 0 & 0 & 1 & 3 & 2 o lugar & 110 lugar \\
\hline GP 2013/2 & 3 & 2 & 2 & 1 & 1 & 2 & 2 lugar & 6ㅇ lugar \\
\hline GP 2014/1 & 3 & 0 & 0 & 1 & 1 & 0 & 1ㅇlugar & 6ㅇ lugar \\
\hline GP 2014/2 & 2 & 2 & 1 & 0 & 1 & 2 & 5o lugar & 9o lugar \\
\hline GP 2015/1 & 1 & 4 & 3 & 0 & 2 & 1 & 3 ㅇ lugar & 110 lugar \\
\hline GP 2015/2 & 2 & 4 & 2 & 1 & 1 & 2 & 3ㅇ lugar & 5ㅇ lugar \\
\hline GP 2016/1 & 4 & 1 & 2 & 0 & 1 & 1 & 10 lugar & 9ㅇ lugar \\
\hline GP $2016 / 2$ & 0 & 2 & 0 & 1 & 2 & 1 & 7ㅇ lugar & 4ㅇ lugar \\
\hline GP 2017/1 & 2 & 0 & 0 & 1 & 1 & 2 & 20 lugar & 5ㅇ lugar \\
\hline GP 2017/2 & 3 & 0 & 1 & 1 & 1 & 3 & 10 lugar & 4ㅇlugar \\
\hline Total & 31 & 20 & 18 & 9 & 14 & 20 & ---- & ---- \\
\hline
\end{tabular}

${ }^{1}$ Resultados: Ou- Ouro; Pr- Prata; Br- Bronze.

Fonte: adaptado de CBDV (2018).

Não há dúvidas que sediar competições de nível nacional auxilia no processo de desenvolvimento da modalidade. Porto Alegre foi por duas vezes sede da etapa nacional do Grand Prix INFRAERO de judô para Cegos, nos anos de 2015 e 2017. Um dos principais legados destes eventos foi a participação da equipe de arbitragem da Federação Gaúcha de Judô (FGJ) em competições específicas de judô para deficientes visuais, aumentando a compreensão dos árbitros sobre o tema, assim como o suporte direcionado aos atletas deficientes visuais durante as competições da FGJ.

Em nível escolar, a única competição nacional de judô paralímpico, ocorre anualmente, desde 2009, dentro do programa das Paralimpíadas Escolares. Durante este período, quatro atletas vinculados a Equipe ACERGS/UFRGS estiveram presentes (CPB, 2018), sendo dois deles atletas do PBL. O Técnico da Equipe ACERGS/ UFRGS e do PBL, foi o responsável técnico da modalidade de judô paralímpico da delegação do Estado do Rio Grande do Sul nas últimas três edições (2015, 2016 e 2017).

O Brasil sediou dois eventos internacionais, em 2017, os Jogos Parapan-Americanos de Jovens e o IBSA Judô American Championships, ambas no Centro de Treinamento Paralímpico em São Paulo. A Equipe ACERGS/UFRGS, presente nos dois eventos, foi representada por dois atletas (um do PBL) que conquistaram três medalhas nestes eventos. Os atletas deficientes visuais do PBL, também competem contra atletas videntes no judô regular e em sua maioria, conquistam medalhas.

\section{Pesquisas científicas}

O pilar nove analisa se há suporte científico por trás das medidas técnicas, fisiológicas, pedagógicas, psicológicas e biomecânicas adotadas pela modalidade. Também analisa se há cooperação entre universidades e a realidade prática dos atletas e treinadores. 
Ao analisar a produção científica online, em português, de modalidades olímpicas e paralímpicas, Souza et al. (2016) encontraram 2.000 artigos sobre as modalidades de verão. Destes, 52 eram referentes aos esportes paralímpicos, com somente três tratando sobre o judô paralímpico. O PBL possui uma inexpressiva produção científica na área de judô paralímpico, o que reflete o contexto atual dos estudos sobre a modalidade nacionalmente. Entretanto, segundo levantamento realizado pela consultoria inglesa Colwiz (2018), intitulado "Olympic Reserarch Medals", o Brasil é o segundo país no mundo no que tange ao número de publicações sobre o judô. Com algumas adaptações na aplicabilidade destes estudos, além do conhecimento empírico adquirido ao longo dos 27 anos de existência, o PBL elaborou uma metodologia de ensino/aprendizagem apropriada para atletas deficientes visuais, capacitando estudantes e profissionais da área no atendimento qualificado a esta população (BUGRE LUCENA, 2017).

\section{CONSIDERAÇÕES FINAIS}

A extensão universitária busca promover a interação entre a universidade e a sociedade, visando o desenvolvimento mútuo, através de atividades de cunho científico, social, educacional, cultural e esportivo. 0 projeto de extensão universitária Bugre Lucena (PBL), ao oportunizar a prática de judô para alunos deficientes visuais, contribuiu para o desenvolvimento da modalidade no Estado. A Equipe ACERGS/UFRGS permaneceu até o ano de 2017, como única equipe de judô paralímpico do Rio Grande do Sul vinculada a CBDV (CBDV, 2017).

O protagonismo nacional da Equipe ACERGS/UFRGS pode ser observado através: da participação em todas as competições da CBDV, no período de 2011 a 2017; no número de atletas inscritos nas competições, figurando sempre entre as maiores delegações; nas conquistas dos títulos por equipe na categoria iniciante, na qual foi cinco vezes campeã. Além disso, tiveram atletas ranqueados entre os melhores das suas categorias, convocados para a seleção brasileira, conquistando títulos nacionais e internacionais. Sediar por duas vezes em Porto Alegre o Grand Prix INFRAERO de Judô para Cegos, nos anos de 2015 e 2017, é outra importante conquista da modalidade no RS, pois apenas São Paulo sediou mais de uma etapa.

Ao descrevermos a modalidade de judô paralímpico do PBL, utilizando os pilares do SPLISS para interpretálo, é possível perceber que o projeto contempla uma parcela dos fatores de sucesso para o alto rendimento. No entanto, o planejamento da modalidade de judô paralímpico do PBL é anual (pilar 2), devido as peculiaridades de um projeto de extensão universitária. O baixo suporte financeiro e sua imprevisibilidade (pilar 1) torna o planejamento e o desenvolvimento da modalidade ainda mais complexo. Com isso o PBL funciona em partes, pela participação de profissionais voluntários (pilar 2), como atletas se dividindo entre treinos e a gestão da ACERGS, além do técnico da Equipe ACERGS/UFRGS (pilar 7). Tais características demonstram uma forma amadora de gestão esportiva. A participação esportiva em todo os níveis (pilar 3), a qualidade das instalações esportivas da ESEFID/UFRGS (pilar 6), o desenvolvimento e qualificação dos técnicos (pilar 7), a participação em todas as competições paralímpicas brasileiras, além da presença constante em competições internacionais (pilar 8) são pontos de destaques no PBL.

Este estudo procurou demonstrar a importância da aproximação dos esportes paralímpicos com projetos de extensão universitária. Além de tornar acessível a comunidade acadêmica os esportes paralímpicos, os projetos de extensão universitária podem também, suprir as demandas encontradas pelas modalidades, viabilizando seu desenvolvimento e manutenção. No que diz respeito a formação de recursos humanos para atuar com o esporte paralímpico, a extensão universitária pode ser um espaço privilegiado, como revela o caso da ESEFID/UFRGS.

\section{REFERÊNCIAS}

ACERGS. ASSOCIAÇÃO DE CEGOS DO RIO GRANDE DO SUL. Esportes. Disponível em < http://acergs. org.br//>. Acessado em: 24 de fevereiro de 2018. 
BRASIL. Rede Nacional do Esporte. Judô. Disponível em: <http://www.brasil2016.gov.br/pt-br/ megaeventos/paraolimpiadas/modalidades/judo>. Acessado em: 24 de fevereiro de 2018.

BROUWERS, J.; SOTIRIADOU, P.; DE BOSSCHER, V. Sport-specific policies and factors that influence international success: the case of tennis. Sport Management Review, Amsterdã, v. 18, n. 3, p. 34358, 2015.

BUGRE LUCENA. Relatório ação de extensão, [5226] - XVI Edição, Bugre Lucena. № do Processo: 230780113630504. Coordenador Alexandre Velly Nunes, Porto Alegre, 2005.

BUGRE LUCENA. Relatório ação de extensão, [33145] - XXVII Edição, Bugre Lucena, 2017. Coordenador Carlos Adelar Abaide Balbinotti, Porto Alegre, 2017.

CAMPANI, D. B.; KRUMEL, V. F.; SCHNEIDER, W. A. Judô para portadores de deficiência visual. Disponível em: <http://congressoanterior.redeunida.org.br/resumos/RE1199-1.pdf >. Acessado em: 24 de fevereiro de 2018.

COLWIZ. Olympics Research Medals. Disponível em: <https://www.wizdom.ai/dashboards/olympicsresearch/judo>. Acessado em: 26 de fevereiro de 2018.

CPB. Comitê Paralímpico Brasileiro. Paralimpíadas Escolares. Disponível em: <http://www.cpb.org. br/>. Acessado em: 26 de fevereiro de 2018.

CBDV. Confederação Brasileira de Deportos de Deficientes Visuais. Judô. Disponível em: <http:// cbdv.org.br/>. Acessado em: 24 de fevereiro de 2018.

DE BOSSCHER, V.; SHIBLI, S.; WESTERBEEK, H.; VAN BOTTENBURG, M. Successful elite sport policies: an international comparison of the sports policy factors leading to international sporting success (SPLISS 2.0) in 15 nations. Aachen: Meyer \& Meyer Sport, 2015.

DE BOSSCHER, V.; DE KNOP, P.; VAN BOTTENBURG, M. SHIBLI, S. A conceptual framework for analyzing sports policy factors leading to international sporting Success. European Management Quarterly, London, v. 6, n. 2, p. 185-215, 2006.

GONSALVES E. P. Conversas sobre iniciação à pesquisa científica. Campinas: Alínea, 2007.

IBGE. Instituto Brasileiro de Geografia e Estatística. Censo - Amostra - Pessoa com deficiência. IBGE, 2010. Disponível em: <https://censo2010.ibge.gov.br/>. Acessado em: 26 de fevereiro de 2018.

IBSA. International Blind Sport Federation. Judô general information, 2018. Disponível em: <http:// www.ibsasport.org>. Acessado em: 24 fev. 2018.

IPC. International Paralympic Comite. All-time paralympic games medal standings - Judo. Disponível em: <https://www.paralympic.org//>. Acessado em: 23 de abril de 2017.

JUDÔ PARA PORTADORES DE NECESSIDADES ESPECIAIS. Relatório ação de extensão, [7317] - Judô para portadores de necessidades especiais. № do Processo: 230780055370681. Coordenador Alexandre Velly Nunes, Porto Alegre, 2006.

LUME. Repositório digital da UFRGS. Disponível em: <http://www.lume.ufrgs.br/ handle/10183/98741>. Acessado em: 23 de abril de 2017

MAZZEI, L. C. Judô de alto rendimento: fatores organizacionais que influenciam o sucesso esportivo internacional. 2015. 166f Tese (Doutorado em Biodinâmica do Movimento Humano) - Escola de Educação Física e Esporte, Universidade de São Paulo, São Paulo, 2015.

PARA-SPLISS. Para-Sport Policy Factors Leading to International Sporting Sucess. Disponível em: $<$ http://www.vub.ac.be/SBMA/sites/default/files/PARA\%20SPPLISS\%202\%20Pager.pdf>. Acessado em: 24 de fevereiro de 2018.

PREPARAÇÃO FÍSICA PARA DEFICIENTES VISUAIS. Relatório ação de extensão, [22772] - Preparação Física para Deficientes Visuais-2013. Coordenador Alexandre Velly Nunes, Porto Alegre, 2013.

URGS. Pro-Reitoria de Extensão Universidade Federal do Rio Grande do Sul. Bolsas. Disponível em: $<$ https://www.ufrgs.br/prorext/apoio-a-extensao/bolsas/>. Acessado em: 26 de fevereiro de 2018.

SOTIRIADOU, P.; GROWTHORP L.; DE BOSSCHER, V. Elite sport culture and policy interrelationships: the case of sprint canoe in Australia. Leisure Studies, London, v. 33, n. 6, p. 598-617, 2013. 
SOUZA, D. L.; SILVA, M. M.; MOREIRA, T. S. “O perfil da produção científica online em português relacionada às modalidades olímpicas e paralímpicas". Movimento, Porto Alegre, v. 22, n. 4, p. 110520, 2016.

SPLISS. Sports Policy Factors Leading to International Sporting Success. Disponível em: <http:// www.spliss.be/>. Acessado em: 24 de fevereiro de 2018.

TRUSZ, R. A.; NUNES, A. V. A evolução dos esportes de combate no currículo do curso de educação física da UFRGS. Movimento, v. 13, n. 1, p. 179-204, 2007.

TRUYENS, J.; DE BOSSCHER, V.; HEYNDELS, B.; WESTERBEEK, H. A resourcebased perspective on countries competitive advantage in elite athletics. International Journal of Sport Policy and Politics, London, v. 6, n. 3, p. 459-89, 2014.

UFRGS. Universidade Federal do Rio Grande do Sul. Projeto Bugre Lucena de judô nas paralimpíadas do Rio 2016. Disponível em: <https://www.ufrgs.br/esefid/site/noticia/328 Projeto Bugre Lucena de Jud E nas Paralimp Aadas do Rio 2016>. Acessado em: 24 de fevereiro de 2018.

VIEIRA, C. de S. Judô paraolímpico: manual de orientação para professores de educação física/ Carmelino de Souza Vieira, Walter Russo de Souza Júnior. Brasília: Comitê Paraolímpico Brasileiro, 2006.

YIN, R. K. Estudo de caso: planejamento e métodos. 22. ed. Porto Alegre: Bookman. 2001.

Autor correspondente: Gustavo Bordin Schumacher

E-mail: gustavo.schumacher@ufrgs.br

Recebido: 09 de abril de 2018.

Aceito: 08 de junho de 2018. 